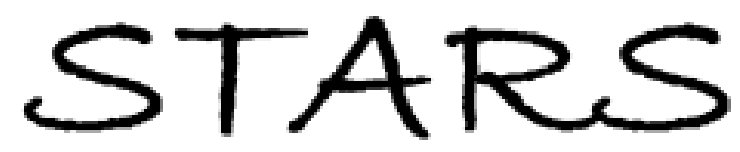

University of Central Florida

STARS

$1-1-2012$

\title{
Role of mechanical loads in inducing in-cycle tensile stress in thermally grown oxide
}

\author{
Rene Diaz \\ University of Central Florida \\ Melan Jansz \\ University of Central Florida \\ Mitra Mossaddad \\ University of Central Florida \\ Seetha Raghavan \\ University of Central Florida \\ John Okasinski
}

Find similar works at: https://stars.library.ucf.edu/facultybib2010

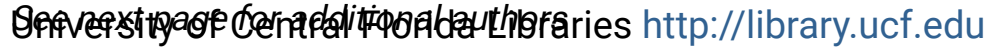

This Article is brought to you for free and open access by the Faculty Bibliography at STARS. It has been accepted for inclusion in Faculty Bibliography 2010 s by an authorized administrator of STARS. For more information, please contactSTARS@ucf.edu.

\section{Recommended Citation}

Diaz, Rene; Jansz, Melan; Mossaddad, Mitra; Raghavan, Seetha; Okasinski, John; Almer, Jonathan; PelaezPerez, Hugo; and Imbrie, Peter, "Role of mechanical loads in inducing in-cycle tensile stress in thermally grown oxide" (2012). Faculty Bibliography 2010s. 2489.

https://stars.library.ucf.edu/facultybib2010/2489

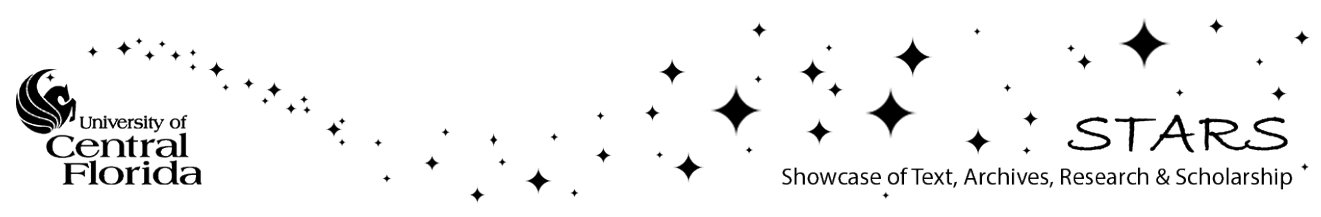




\section{Authors}

Rene Diaz, Melan Jansz, Mitra Mossaddad, Seetha Raghavan, John Okasinski, Jonathan Almer, Hugo

Pelaez-Perez, and Peter Imbrie 


\section{Role of mechanical loads in inducing in-cycle tensile stress in thermally grown oxide}

Cite as: Appl. Phys. Lett. 100, 111906 (2012); https://doi.org/10.1063/1.3692592

Submitted: 02 January 2012 . Accepted: 20 February 2012 . Published Online: 14 March 2012

Rene Diaz, Melan Jansz, Mitra Mossaddad, Seetha Raghavan, John Okasinski, Jonathan Almer, Hugo Pelaez-Perez, and Peter Imbrie

\section{ARTICLES YOU MAY BE INTERESTED IN}

Synchrotron X-ray measurement techniques for thermal barrier coated cylindrical samples under thermal gradients

Review of Scientific Instruments 84, 083904 (2013); https://doi.org/10.1063/1.4817543

Stress and structural damage sensing piezospectroscopic coatings validated with digital image correlation

AIP Advances 5, 037139 (2015); https://doi.org/10.1063/1.4916760

Calculations of single crystal elastic constants for yttria partially stabilised zirconia from powder diffraction data

Journal of Applied Physics 116, 053509 (2014); https://doi.org/10.1063/1.4891714

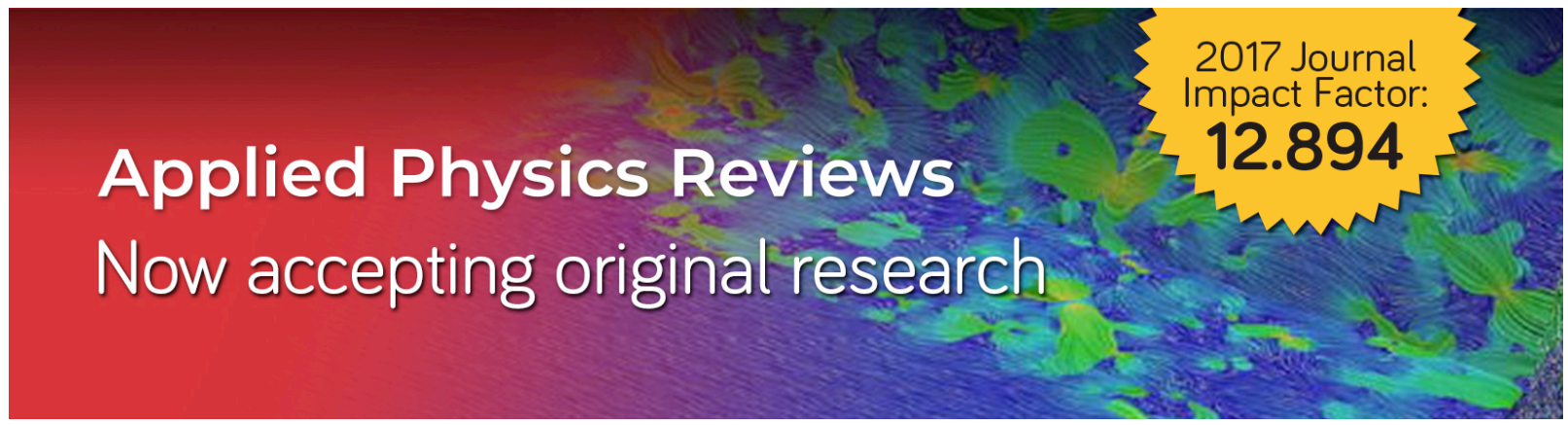




\title{
Role of mechanical loads in inducing in-cycle tensile stress in thermally grown oxide
}

\author{
Rene Diaz, ${ }^{1}$ Melan Jansz, ${ }^{1}$ Mitra Mossaddad, ${ }^{1}$ Seetha Raghavan, ${ }^{1, a)}$ John Okasinski, ${ }^{2}$ \\ Jonathan Almer, ${ }^{2}$ Hugo Pelaez-Perez, ${ }^{3}$ and Peter Imbrie ${ }^{3}$ \\ ${ }_{1}^{1}$ Mechanical, Materials and Aerospace Engineering Department, University of Central Florida, Orlando, \\ Florida 32816, USA \\ ${ }^{2}$ X-ray Science Division, Advanced Photon Source, Argonne National Laboratory, Argonne, Illinois 60439, \\ USA \\ ${ }^{3}$ School of Aeronautics and Astronautics, Purdue University, West Lafayette, Indiana 47907, USA
}

(Received 2 January 2012; accepted 20 February 2012; published online 14 March 2012)

\begin{abstract}
Experimental in situ synchrotron x-ray diffraction results tracking the strain behavior of the various layers during a cycle, under thermo-mechanical conditions are presented in this work. The quantitative strain measurements here show that the thermally grown oxide briefly experiences in-plane tensile stress $\left(\sigma_{22}=+36.4 \mathrm{MPa}\right)$ with increased mechanical loading during ramp-up in the thermal cycle. These findings are the first in situ experimental observations of these strains under thermo-mechanical conditions, envisaged to serve as a catalyst for crack initiation. The depth resolved measurements of strain taken during applied thermal and mechanical load in this work are a significant step towards achieving realistic testing conditions. (C) 2012 American Institute of Physics. [http://dx.doi.org/10.1063/1.3692592]
\end{abstract}

Thermal barrier coatings (TBCs) on high temperature components allow for increased operating surface temperatures leading to efficiency in turbines. Substantial progress in the understanding of TBCs point to the significant stress gradients and high compressive strains in the thermally grown oxide (TGO) as factors leading to failure of the coatings. ${ }^{1-7}$

Studies of thermo-mechanical fatigue (TMF) in turbine blades have, in some cases, included the effects of coatings on the blade life model. ${ }^{11-14}$ Conversely, however, in microstructural TBC research, only a limited number of studies attempt to include factors such as the axial loading due to centrifugal forces ${ }^{8,9,15,16}$ and effects of axial stress in the substrate $^{17}$ on TBC degradation. In these ex-situ studies, cracks found to initiate at the bond coat/TGO interface were attributed to possible high in-cycle tensile strains in the TGO that occur with mechanical loads. ${ }^{8}$ More commonly, high compressive strains in the TGO have been attributed to thermal expansion mismatch between the different materials that make up the TBC layers and have been related to life fraction. ${ }^{18-20}$ It has been suggested that the often neglected axial loads applied at high temperature in a thermomechanical fatigue load cycle may overcome the intrinsic compressive TGO stress at some point within the cycle to result in crack initiation and degradation. ${ }^{9,16}$ This is best monitored through in situ measurements within the thermal cycle. Recognizing the need to track oxide growth and behavior through in situ studies, Veal et al. ${ }^{7}$ obtained x-ray diffraction (XRD) readings from oxide formation on an FeCrAlY substrate during a cycle. Notwithstanding the absence of the interplay of the topcoat strain from the multilayer TBC configuration, these pioneering studies verify tensile strains in the early oxide as it transitions to $\alpha$-alumina, illustrating the significance of in situ measurements.
Besides their significant potential for high resolution in situ measurements, $\mathrm{x}$-ray diffraction methods at synchrotron facilities have been used on TBC specimens for studies involving the depth profile of strain on pre-cycled plasmasprayed TBC specimens ${ }^{21-23}$ revealing the variation of the strain across the layers. In the work presented here, a combination of depth resolved XRD readings across the TBC layers taken during a thermal cycle has led to the elucidation of the role of applied mechanical loads on the strain evolution as illustrated in Fig. 1.

The TBC samples used in the experiments performed for this work were electron beam physical vapor deposition (EB-PVD) coated specimens prepared from one inch diameter CMSX-4 Ni-base super-alloy discs with a platinummodified nickel-aluminide bond coat $(50 \mu \mathrm{m})$ and 7 weight percent Yttria-stabilized zirconia (7YSZ, $125 \mu \mathrm{m}$ ). Sample specimens were machined to ASTM standard E 8/E 8M. ${ }^{29}$ The experiments were performed at the 1-ID beam line at the Advanced Photon Source (APS) at Argonne National Laboratory. High energy x-rays of $86 \mathrm{keV}$ were used to obtain depth-resolved high resolution strain measurements in short data collection times. Figure 2(a) illustrates a schematic of the experimental setup where an MTS 858 electromechanical testing system on an XYZ stage provided the necessary sample motion and orientation, an infra-red furnace provided the high temperature environment, and a $2 \mathrm{D}$ XRD detector with a resolution of 2048 pixels $\times 2048$ pixels was used to collect the data of the diffraction rings. The sample was mounted as illustrated in Figure 2(b) in the load frame using pins and the temperature monitored using thermocouples. Depth-resolved data was collected for applied stress values of $16 \mathrm{MPa}, 32 \mathrm{MPa}$, and $64 \mathrm{MPa}$. Using the XYZ stage of the MTS machine, data could be collected with a $40 \mu \mathrm{m}$ width depth resolution across the layers and interfaces along the $S_{1}$ axis. The dimensions of the x-ray beam were $40 \mu \mathrm{m}$ by $30 \mu \mathrm{m}$ as illustrated in Figure 1(a).

a)Electronic mail: seetha.raghavan@ucf.edu. 


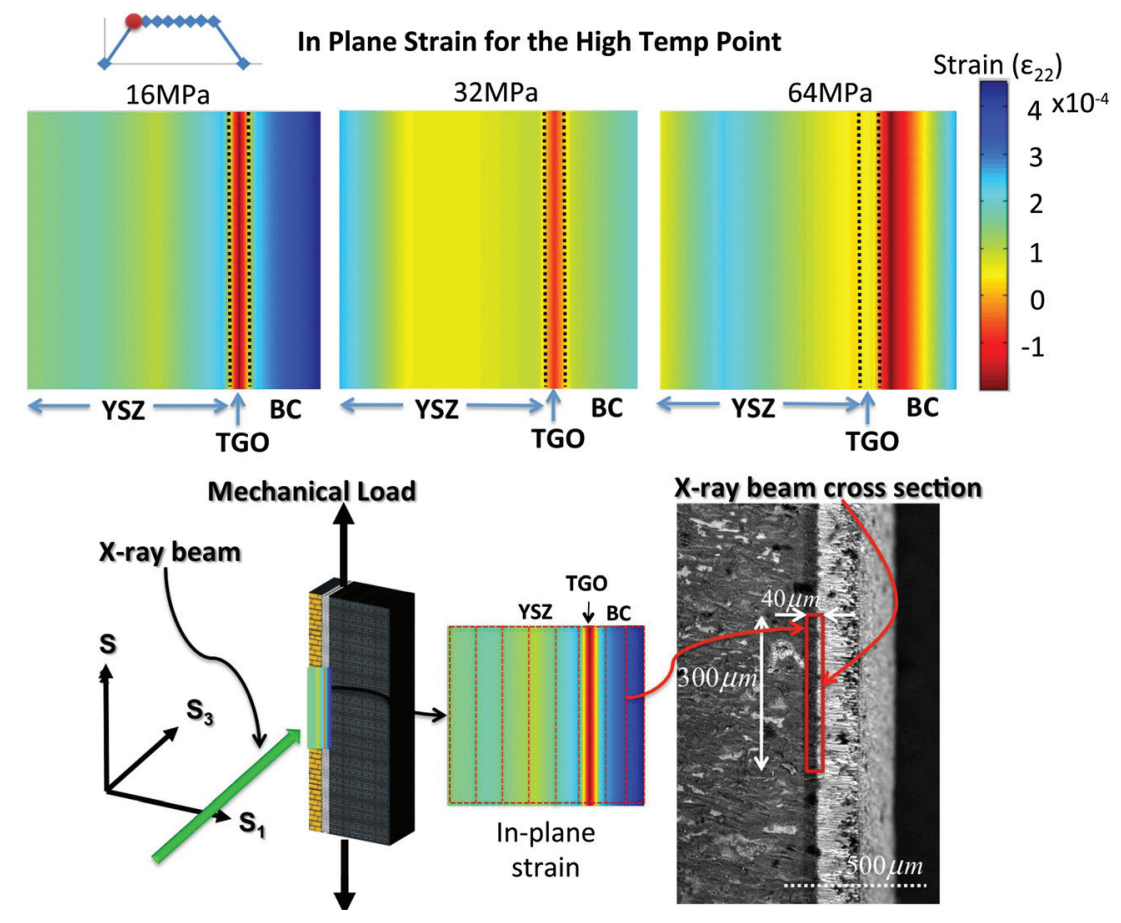

FIG. 1. (Color) Strain as "seen" through the x-ray beam window. The depth profile highlights interface strains and illustrates the TGO strain evolving from compressive to tensile with corresponding increasing externally applied stress.
Considering the co-ordinate system presented in Figure 2(a), the layers of the coating system are oriented along the $S_{1}$ axis on the nickel super-alloy substrate and the path of the $\mathrm{x}$ ray beam was along the $S_{3}$ axis.

For each time step in the thermal cycle, approximately 10 data points were collected and this was repeated for all three (16 MPa, $32 \mathrm{MPa}$, and $64 \mathrm{MPa}$ ) different loading conditions. Example diffraction patterns collected for the different layers in a cycle for a thermo-mechanical loading condition are shown in Figure 2(c). These diffraction rings were studied first to identify the peaks as illustrated in Figure 3(c). These recognized peaks were then analyzed to obtain the biaxial strain plots and Figures 3(a) and 3(b) illustrates these plots for the TGO ( $\alpha$-alumina) verified using two different crystallographic planes. The biaxial strain plots were used to determine the strain values shown in Figure 4 with a typical error range indicated on the example data in the plots of Figures 3(a) and 3(b).

Strain values for each of the load conditions over the various layers are shown in Fig. 4 at three consecutive tem- perature points within the thermal cycle. At room temperature, the magnitude of the TGO stresses fall within the range of measured values by other researchers ${ }^{18}$ with minimal variations between the different applied mechanical stresses. At the ramp-up temperature, for an applied mechanical stress of $16 \mathrm{MPa}$, the TGO strain remains in the compressive region while experiencing a state of strain relief. This strain relief in the TGO is more pronounced at the higher applied stress of $32 \mathrm{MPa}$. With an applied stress of $64 \mathrm{MPa}$, for the ramp-up position, tensile in-plane strain was observed corresponding to an equivalent stress of $\sigma_{22}=+36.4 \mathrm{MPa}$. This significant finding is accompanied by quantitative depth-resolved values of strain, within the neighboring topcoat and bondcoat layers as it evolves during the thermo-mechanical cycle. The in situ nature of the experiment played an important part in capturing the TGO tensile strain during the high temperature or ramp-up point within the cycle. This is an important step towards achieving conditions and outcomes that represent, more closely, the in-service behavior of TBC systems. The significance of these first measurements of thermo-
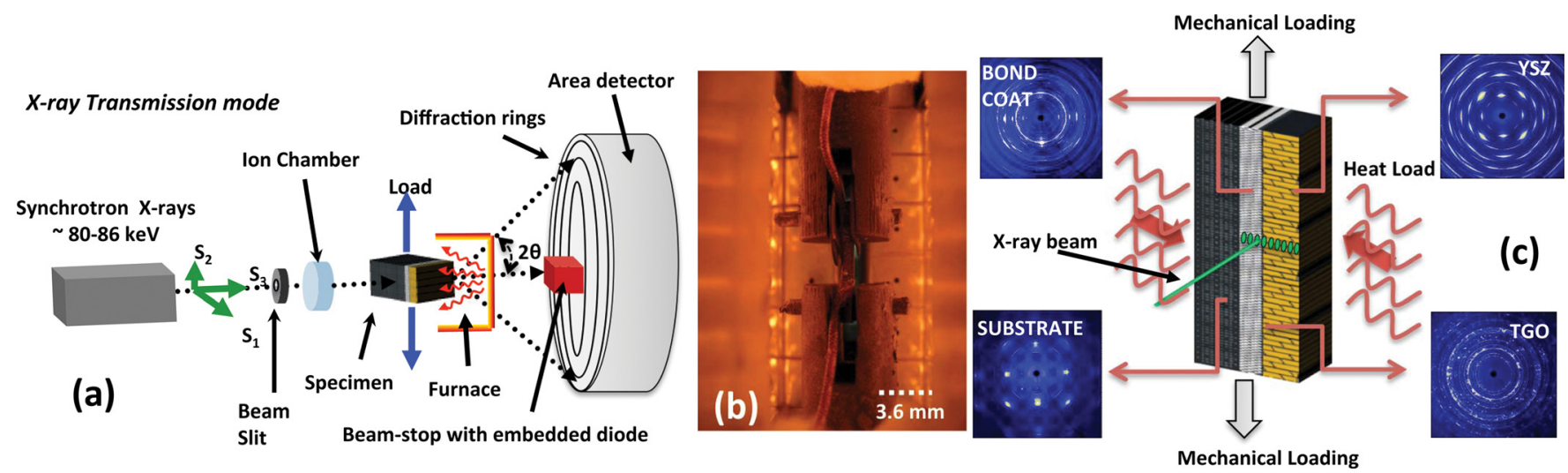

FIG. 2. (Color online) (a) Schematic representation of the experimental setup. (b) Image of the sample attached to the thermo-mechanical experimental setup. (c) Example diffraction rings for the different layers in the TBC system. 

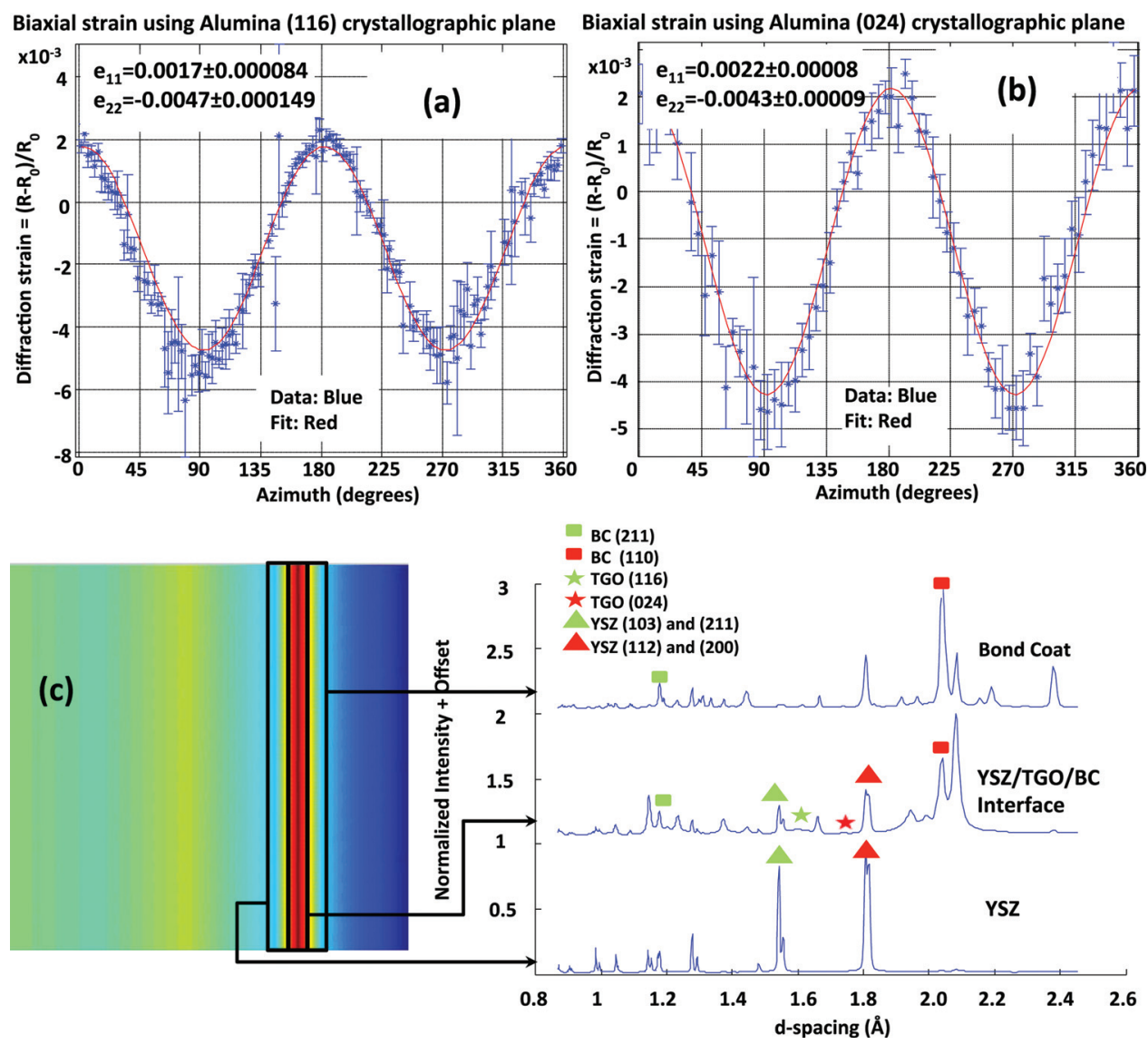

FIG. 3. (Color) (a) TGO biaxial strain obtained for a particular data point using (116) crystallographic plane. (b) TGO biaxial strain verified for the same data point using (024) crystallographic plane. (c) Representative contour plot illustrating the depth-resolved strains obtained using XRD peaks identified for the various layers. mechanical load induced tensile strains in the TGO, their origins and impact on the long-term life of the TBC are discussed further.

Ex-situ characterization of TBCs represents the observation, through microscopy, of the sum of a multitude of effects $^{24}$ some of which the in situ results presented here can offer reasoning towards. The in-plane tensile strain within the TGO layer presented in Figure 1 is a response previously suggested by Tzimas et al. ${ }^{8}$ from ex-situ microstructural comparisons of samples with high and low applied mechanical loads. Whereas low mechanical strain was linked with delamination failure, high applied loads were associated with tensile strain induced bond coat cracking in a direction perpendicular to the loading. Our in-cycle strain evolution

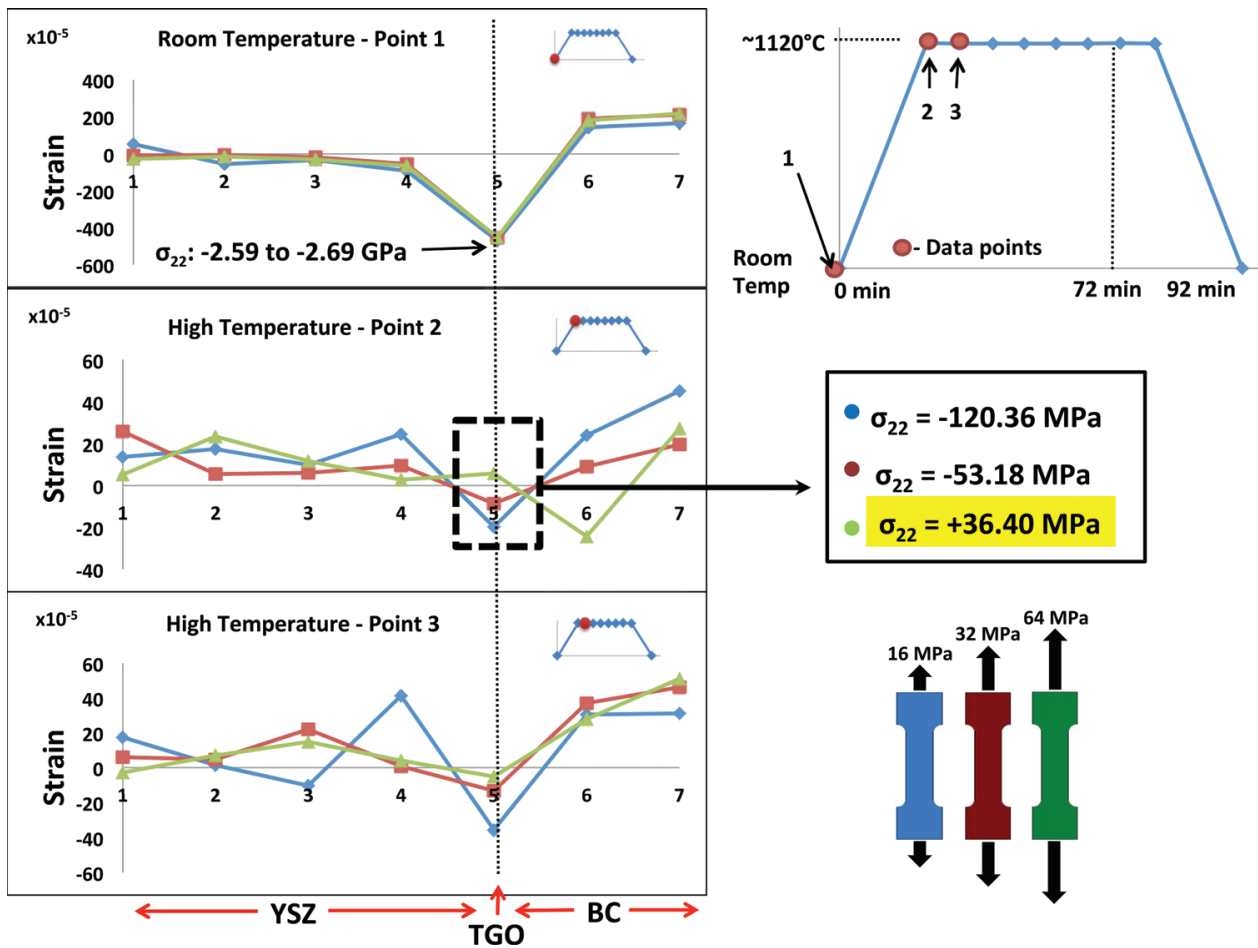

FIG. 4. (Color) In-plane strain values over the depth of the TBC layers taken in situ during the thermo-mechanical cycle (corresponding TGO in-plane stresses are highlighted in the box). 
results insinuate that, with high applied mechanical loading, cracks may initiate within the TGO during the tensile strain condition at high temperature point 2 . This will eventually lead to propagation within the bond coat at high temperature point 3 and onward in the cycle where the TGO strain returns to a compressive state and tensile strain dominates in the bond coat. This strain behavior between the TGO and bond coat illustrated in Figure 1 has been observed in the ex-situ synchrotron study by Thornton et al. where it was demonstrated that residual stresses in the TBC coating must be balanced by opposing stresses in the bond coat and substrate. ${ }^{21}$ The effect of mechanical loading was also seen in the ex-situ microscopy studies by Bartsch et al. ${ }^{9,16}$ on a TBC system subjected to thermal gradient mechanical fatigue testing where cracks initiated in the TGO, perpendicular to the applied mechanical load, were attributed to possible in-cycle tensile strains and they gradually grew into the neighboring layers. In-phase thermo-mechanical tests performed by Kitazawa et al. ${ }^{25}$ showed a similar failure mechanism highlighting the effect of mechanical loads on the coating life.

Numerical simulations have the benefit of providing incycle and quantitative results through the depth although their accuracy is reliant on some form of validation. Simulations under thermal gradients carried out by Bartsch et al. ${ }^{9,10,16}$ show that, at high temperature, an imposed axial stress of $100 \mathrm{MPa}$ results in a strain relief of about $392 \mathrm{MPa}$ in the TGO. This rate of strain relief at high temperature is comparable to our measurements of approximately $3.2 \mathrm{MPa}$ per unit applied axial stress. These findings were reiterated by the TBC simulation models of Tzimas et al. ${ }^{8}$ showing strain relief at maximum applied stress which results in a tensile TGO value at the concave interfaces of the modeled interface roughness.

The origin of the tensile strains is best described as the effect of applied mechanical loads overcoming the inherent compressive strains within the TGO. Studies ${ }^{16}$ have shown tensile stresses present in the TGO are time and temperature dependent which are non-linearly coupled. Factors such as the TGO growth stresses, TGO structure, and loading sequence contribute towards the overall TGO stresses. Of significance here is the ability to correlate these measured incycle strains to the time within the cycle at which they occur. In situ measurements bring with them the benefit of tracking such time-dependent events. In this case, the ramp-up point, has been identified as a critical point within the cycle for initiation of through-thickness cracks. This reiterates the view that there is a significant influence of the thermal cycle conditions including heating rates on the coating life. ${ }^{26}$

The effect of mechanical loads on in-cycle strain range observed here, provides an insight into the long term effects in terms of reduced coating life. This is supported by findings from cyclic strain studies through damage evaluation. ${ }^{27,28}$ The quantitative in-cycle strain range measurements of the TGO achieved in this work, when taken at various life fractions can be integrated with current models to improve life prediction.

In summary, increasing applied mechanical load induces strain relief at the high temperature point in the cycle such that beyond a critical thermo-mechanical loading condition, the TGO exhibits tensile strain. With quantitative strain values, the findings highlight the ability of high-resolution in situ methods to address the paucity of information that exists between cycles. It further reiterates the need to establish realistic testing conditions for the better understanding of coating strains to develop methods for improving their durability.

This material is based upon work supported by the National Science Foundation under Grant No. 1125696. Use of the Advanced Photon Source, an Office of Science User Facility operated for the U.S. Department of Energy (DOE) Office of Science by Argonne National Laboratory, was supported by the U.S. DOE under Contract No. DE-AC0206CH11357.

${ }^{1}$ D. Clarke, R. Christensen, and V. Tolpygo, Surf. Coat. Technol. 94-95, 89 (1997).

${ }^{2}$ A. Evans, D. Mumm, J. Hutchinson, G. Meier, and F. Pettit, Prog. Mater. Sci. 46, 505 (2001).

${ }^{3}$ C. Guerre, L. Remy, and R. Molins, Mater. High Temp. 20, 481 (2003).

${ }^{4}$ P. Y. Hou, A. P. Paulikas, and B. W. Veal, in Proceedings of the 6th Symposium on High Temperature Corrosion and Protection of Materials, Les Embiez, France, 16-21 May (2004).

${ }^{5}$ J. Nychka and D. Clarke, Surf. Coat. Technol. 146-147, 110 (2001).

${ }^{6}$ J. Nychka, T. Xu, D. Clarke, and A. Evans, Acta Mater. 52, 2561 (2004).

${ }^{7}$ B. W. Veal, A. P. Paulikas, and P. Y. Hou, Nature Mater. 5, 349 (2006).

${ }^{8}$ E. Tzimas, H. Mullenjans, S. D. Peteves, J. Bressers, and W. Stamm, Acta Mater. 48, 4699 (2000).

${ }^{9}$ M. Bartsch, B. Baufeld, S. Dalkilic, L. Chernova, and M. Heinzelmann, Int. J. Fatigue 30, 211 (2008).

${ }^{10}$ M. T. Hernandez, D. Cojocaru, M. Bartsch, and A. M. Karlsson, Comput. Mater. Sci. 50, 2561 (2011).

${ }^{11}$ E. Chataigner and L. Remy, "Thermomechanical Fatigue Behavior of Coated and Bare Nickel-Based Superalloy Single Crystals," Thermomechanical Fatigue Behavior of Materials, ASTM STP 1263 (1996), pp. 3-25.

${ }^{12}$ Y. Zhang, D. Knowles, and P. Withers, Scr. Mater. 37, 815 (1997).

${ }^{13}$ M. Shenoy, A. Gordon, D. McDowell, and R. Neu, J. Eng. Mater. Technol. 127, 325 (2005)

${ }^{14} \mathrm{~J}$. Bressers, K. Ostolaza, and M. Arana, in Elevated Temperature Coatings: Science and Technology II, Anaheim, California, 4-8 February (The Minerals and Metals Society, 1996), pp. 275-285.

${ }^{15}$ P. Moretto, J. Bressers, and D. J. Arrell, Mater. Sci. Eng., A 272, 310 (1999).

${ }^{16}$ M. T. Hernandez, A. M. Karlsson, and M. Bartsch, Surf. Coat. Technol. 203, 3549 (2009).

${ }^{17}$ M. Baker, J. Rosler, and E. Affeldt, Comput. Mater. Sci. 47, 466 (2009).

${ }^{18}$ S. Sridharan, L. Xie, E. H. Jordan, and M. Gell, Surf. Coat. Technol. 179, 286 (2004).

${ }^{19}$ J. Nychka, D. Clarke, S. Sridharan, E. Jordan, M. Gell, M. Lance, I. S. C. J. Chunnilall, S. Saunders, R. Pillan, V. Sergo et al., Surf. Coat. Technol. 163-164, 87 (2003).

${ }^{20}$ A. Selcuk and A. Atkinson, Mater. Sci. Eng., A 335, 147 (2002).

${ }^{21}$ J. Thornton, D. Cookson, and E. Pescott, Surf. Coat. Technol. 120-121, 96 (1999).

${ }^{22}$ J. Thornton, S. Slater, and J. Almer, J. Am. Ceram. Soc. 88, 2817 (2005).

${ }^{23}$ C. Weyant, J. Almer, and K. Faber, Acta Mater. 58, 943 (2010).

${ }^{24}$ K. A. Marino, B. Hinnemann, and E. A. Carter, Proc. Natl. Acad. Sci. U.S.A. 108, 5480 (2011).

${ }^{25}$ R. Kitazawa, M. Tanaka, Y. Kagawa, and Y. Liu, Mater. Sci. Eng., B 173, 130 (2010).

${ }^{26}$ B. Heeg, V. K. Tolpygo, and D. R. Clarke, J. Am. Ceram. Soc. 94, S112 (2011).

${ }^{27}$ P. K. Wright, Mater. Sci. Eng., A 245, 191 (1998).

${ }^{28}$ H. Brodin, M. Jinnestrand, S. Johansson, and S. Sjöström, Thermal Barrier Coating Fatigue Life Assessment in Fatigue, May 14-19, Atlanta (Elsevier, 2006).

${ }^{29}$ R. Diaz, M. Mossaddad, A. Bozan, S. Raghavan, J. D. Almer, J. Okasinski, H. Palaez-Perez, and P. K. Imbrie, in Proceedings of the 49th AIAA Aerospace Sciences Meeting, Orlando, Florida, 4-7 January 2011. 